\title{
TWO NOTIONS OF SHAME
}

\section{Y. Sandy Berkouski}

\begin{abstract}
On most accounts present in the literature, the complex experience of shame has the injury to self-esteem as its main component. A rival view, originally propounded by St Augustine, relates shame to the structure of human agency, and more specifically, to the conflict between will and desire. A recent version of this view developed by David Velleman relates shame to the capacity of self-presentation and the need for privacy. I examine two different interpretations of Velleman's theory and argue that neither suggests a credible alternative to the received view.
\end{abstract}

\section{Hobbesian theories of shame}

Assume that a person has a certain idea of his own self. He has formed certain beliefs about his physical capacities, his intellectual capacities, his standing in the society, his achievements, his relationships with his friends and family members. Then we say that he is in possession of a self-assessment theory providing him with a scale for grading his various qualities, relations, and activities. Each of these grades is accompanied by value ascriptions: the person should have formed beliefs about how much value each of the properties he attributes to himself is supposed to carry. There would be occasions when at least one of these values decreases. On such occasions the person would become aware that his capacities or achievements are not as significant as he thought they were. Given that those capacities and achievements carry at least some value in the agent's eyes, his overall self-esteem would decrease. The emotional reaction to this decrease in value is shame. The decrease itself can come from a number of sources. It can be a result of the agent's own action, of an action directed at him, or even of someone else's action directed at some third party.

Shame is a result of a procedure of self-evaluation in which the agent is engaged in appraising his own worth. Where, as a result of that appraisal, the agent's opinion of his worth - what we call his 
'self-esteem' - decreases, shame must soon ensue. ${ }^{1}$ This idea is behind what I will call 'Hobbesian theories' of shame. The simplest version is just this:

H1. Shame is an emotional response to a decrease of self-esteem. ${ }^{2}$

This formula faces two kinds of pressure. ${ }^{3}$ On the one hand, it fails to assign any role whatsoever to the spectator. Some of the most conspicuous instances of shame are those where someone is caught in an act he deems shameful, or when the 'defect in ability' is brought to the attention of a spectator. This difficulty can be made more precise by stressing the distinction between shame and disappointment in oneself. The latter (call it 'selfdisappointment') can similarly be identified with injury to selfesteem. Sadness, depression, or the desire to improve one's performance may all be manifestations of self-disappointment. Similar features could also be ascribed to shame. If, however, shame is not to be identified with self-disappointment, the formula $\mathrm{H} 1$ fails to say why.

On the other hand, a person should be able to experience shame in perfect solitude. A person engaged in masturbation or in watching pornographic materials may experience shame though he neither expects any actual censure from others, nor imagines anyone in particular censuring him.

To deal with these pressures, we can insert various constraints in the right-hand side of the biconditional. For example:

H2. Shame is a response to a decrease of self-esteem caused by observing one's actions through the eyes of others.

H3. Shame is a response to a decrease of self-esteem when the parameters of one's self-esteem are derived from an external canon of norms. ${ }^{4}$

1 Throughout this paper I ignore the distinction between 'self-esteem' and 'selfrespect' which, to my mind, has produced a massive confusion in the shame literature.

See Leviathan VI.

3 They are discussed at length in Deigh (1996) and Williams (1993) respectively.

4 These and other variations of H1 are defended, e.g., in Rawls (1999), Williams (1993), Taylor (1985), Kekes (1993), Miller (1993). 


\section{Augustinian theories of shame}

I am not going to examine the relative merits of the Hobbesian formulae described in $\$ 1$. Nor am I going to defend either of these particular suggestions as the only viable way of distinguishing between shame and self-disappointment. My purpose here is limited to comparing the broadly Hobbesian approach to what appears to be an alternative way of thinking about shame originating with St Augustine. ${ }^{5}$ Observe that under all different modifications of the Hobbesian view, the central explanatory link between shame and self-esteem remains invariant. What varies are the ways self-esteem should be affected, or the ways the parameters of self-evaluation should be determined, for shame to arise. The least common denominator of Hobbesian theories is, therefore, neither the idea that the shamed subject should be 'seen by others', nor the idea that shame is determined by extant social norms. It is rather the idea that shame is a function of self-evaluation and self-esteem.

By contrast, the main idea behind the Augustinian view is to connect shame to the essential conditions of human agency. Augustine himself traces the origin of shame to the drama in the Garden of Eden. Before the fall humans could exercise voluntary control over their sexual desire and over the very movement of their sexual organs. The consumption of the fruit produced an alteration in their natures and led to the loss of that control. As a result, Adam's nudity, with its unwilled erections prominently displayed, became shameful for him. The most painful punishment inflicted by God on Adam and Eve was in disconnecting will from desire. What the person wills is not what he wants, says Augustine, and what other punishment could be more severe? ${ }^{6}$

This fall from grace presumably extends to other desires, too, that have gained the power to resist the will. Experiences of shame must be traced to those incidents of insubordinate desires taking control of the person's behaviour. So, if occasions of shame are exactly those occasions where we succumb to a desire despite our will to resist it, then the view could be expressed thus:

A1. Shame is a response to acting on a desire that conflicts with one's will.

See City of God XIV.

Though in XIV.15 Augustine tends to emphasise the conflict between will and bodily movements, he is careful to observe that no such movement would be possible without an antecedent desire. 
But this formula is far too simple. In the first place, there are situations where we experience shame without having any desire getting out of control. If I become aware of my intellectual inferiority, I am likely to be ashamed - but no desire/will conflict should be blamed for this. Secondly, for an agent to be ashamed of a rebellious desire he must already have a negative view of that desire. Suppose the agent's will is to maintain his diet, but the desire to eat the cake proves too strong. These facts are not sufficient to predict that the agent should experience shame upon eating the cake.

Nothing much, I think, can be said about the first concern. As for the second, we could supplement A1 to include an explicit condition referring to the value of the rebellious desire:

A2. Shame is a response to acting on a desire which conflicts with one's will and which has a low ranking in one's valuational system.

A little reflection would show, however, that this formula pulls us towards a Hobbesian theory. The formula H3, for instance, is able to allocate to desires an important role in generating shame. The explanation begins with an assumption that the worth of a person is constantly threatened by desires spinning out of control. A person unable to resist his desires is judged as less valuable than a person who can resist them. This is a familiar theme explored by past moralists. The person's idea of self-worth provides a key explanatory link: the person must already be convinced that being ruled by desires, or perhaps by only some of the desires, reduces his worth. This possibly unarticulated belief, together with the actual reign of desire, brings about the phenomenon of shame.

\section{Shame and psychic conflict}

Augustine's theory seems especially suitable for explaining powerful and conspicuous instances of shame having to do with sex and sexual desire. But exactly with these situations we observe a glaring omission. Sexual intercourse, for example, is shameful when conducted in public, but not so when in private. Augustine is keenly aware of this fact when he says that even marital intercourse has to be done in private to avoid shame. The function of privacy presents a problem, though. If shame consists in surren- 
dering to rebellious desires, why should such surrender be not shameful away from the gaze of the audience?

Put generally, the features of agency inducing shame should be sensitive to the conditions of privacy. The factors of shame as described by A1 and A2 obtain in private no less than in public. No Augustinian theory can, therefore, be adequate unless it explains that sensitivity. Recently David Velleman has defended an alternative and rather complex version of the Augustinian theory. It makes the concern of privacy an essential element of shame. $^{7}$

Velleman gives an interpretation of the Biblical story subtly different from Augustine's. The effect of the forbidden fruit was not in the mere modification of the desire and will relationship. The novelty was the emergence of the will itself. Adam and Eve, by eating the fruit, gained the ability to disobey their instincts (and the Lord's commands). This ability of choice amounts to what the Bible described as the knowledge of good and evil.

On Velleman's view, an agent equipped with will has the ability to resist his instincts, control his desires, and disobey God's commands. By exercising this voluntary ability, he can choose, for instance, which desire to satisfy, and on what occasion. And in particular, he can choose which desire to satisfy and which to resist in the presence of others. Thus the agent 'compiles a profile', as Velleman puts it, of the commitments, preferences, activities, that are to be displayed in public, and a profile of those that should be pursued in private. The former constitutes the public image we present in social interactions. This distinction between the public and the private profiles is not arbitrary. Its purpose is to maintain the status of a candidate for social intercourse, of a 'self-presenting agent'. We wish to present ourselves to others in a coherent and intelligible way in order for us to be recognised as legitimate participants in social practices. The failure of doing so will endanger our cooperation with others, and ultimately, our survival. ${ }^{8}$ Shame is occasioned by the failure of protecting that separation between the public image and the rest of our features.

\footnotetext{
See Velleman (2006a). A similar development of Augustinian ideas is in the writings of Mario Jacoby who is influenced by the psychology research going back to Tomkins (2008) and ultimately to Darwin (1890). See Jacoby (1994:16-23). Velleman provides a far more compelling philosophical rendering of this 'other' view on shame.

8 See Velleman (2006a:55). The same idea is in Gibbard (1990:138).
} 
Where does this all leave us? To get a better grip on Velleman's ideas, let me first formulate a view which, I believe, is not the one defended by Velleman. Consider the following:

H4. Shame is a response to a failure in protecting one's reputation.

Occasions of the agent's shame are exactly the occasions of his damaged reputation. The agent engaged in social interactions first forms an idea of what qualities should be attributed to him by his partners in those interactions. He then invests in a continuous effort to create and defend his public image. That effort is of course independent of the concern of actually having those qualities. Why his public image diverges from his private image, why he would sometimes present himself to others in a way different from the way he presents himself to himself, can readily be explained. He may wish to earn the approval of others with the view of securing material benefits from them. Or perhaps such approval is for him a matter of psychological need. The concrete parameters of this approval are, at all events, contingent. In one community people appreciate sexual modesty, in another community promiscuity is in fashion. The agent would build his public image in accordance with the extant preferences, often whimsical but always intelligible, of his community.

I will return to $\mathrm{H} 4$ in $\$ 5$. Right now I am going to assume that it is not the view defended in Velleman (2006a). There is prima facie sound textual evidence for this interpretation. Velleman's discussion departs from Augustine ("the philosopher who comes closest to understanding shame, in my view, is St. Augustine", he says in page 49). The disobedience of bodily desires to the will constitutes a failure in the maintenance of the self-presenting image. By contrast, $\mathrm{H} 4$ allocates no theoretical role to the essential properties of agency, and so severs itself from the Augustinian idea of psychic conflict that presumably animates Velleman's theory. ${ }^{9}$ Instead of H4, I attribute to Velleman a formally less neat proposal explicitly listing the features of agency that ensure the possibility of shame:

9 Velleman appears to reject $\mathrm{H} 4$ in page 55 where he contrasts self-presentation with the presentation of a "particular public image". The emphasis should be on 'particular'. 
A3. Shame is the agent's response to a situation having the following characteristics: (i) some of agent's desires, but not others, are suitable for social cooperation, (ii) the agent has isolated the desires to be satisfied in public, (iii) the agent has created his self-presenting image largely on the basis of those desires, (iv) the agent's self-presenting image was adjusted, through his failure, to include some elements he deems not suitable to be revealed in public.

We cannot, on this view, understand the phenomenon of shame in separation from the concepts of cooperation, will, desire, and privacy. The condition (i) places the experience of shame in an intrinsically social context. The condition (ii) is called to reflect the voluntary capacity of agency. The condition (iii) establishes the umbilical cord connecting A3 to the original Augustinian view. The condition (iv) links shame to violations of privacy and emphasises the agent's own failure in these violations.

\section{Some objections to Velleman's theory}

Having identified Velleman's proposal, let me now say why I find it ultimately no more successful than Augustine's. I will conduct the discussion under a number of rubrics.

Biblical motivation. Since Velleman devotes considerable space to the events in Eden, a brief comment is in order on his proposed reading of them. ${ }^{10}$ The motivation for A3 comes from the claim that Hobbesian theories are unable to explain the very first

10 The original sin incident received close scrutiny in the rabbinic literature. There is, as expected, no consensus on the relationship between shame, will, desire, and moral knowledge. St Augustine's reading of the incident is evidently shared by Targum Yerushalmi and Midrash Rabba (in Genesis 2:25). Rashi concurs and says that Adam and Eve had no shame prior to eating the forbidden fruit, since they had no 'evil desire'. The fruit put that desire into them. And Sforno, in a claim virtually identical to Augustine's, says that before the fall the limbs obeyed only the will of the person. Sexual acts were like the necessary acts of eating and drinking, and the sexual organs were perceived to be no different from mouth, face, or hands. Later in 3:7 he also argues that Adam covered himself upon realising that the sexual organs 'from now on' will lead to harmful and 'insignificant' pleasures.

A view similar to Velleman's is defended by Nachmanides (Ramban) in the commentary on 2:9. Before the fall, says Nachmanides, Adam naturally acted in the right way. His acts were in that akin to the acts of the angels by being devoid of love and hatred. The forbidden fruit created the will (ratzon) and inclination (hefetz). Whoever eating it would have been able to choose between performing an action and not performing it, and therefore to choose between the good and the evil. (These commentaries on the Genesis are contained in the standard edition of Mikraot Gedolot.) 
instance of shame in Eden. The central episode is in the Genesis 3:10 where Adam is said to be hiding from the Lord in the fear of being discovered naked which he presumably finds shameful. While the shame of nudity within a society can be enforced by social conventions (at least partially grounding one's self-esteem), there were no such conventions in Eden. So Adam could not possibly have a lower self-esteem on the account of his nudity.

However, what we know about Adam before 3:10 does not sit well with his interpretation. For already in 3:7 we are told that Adam and Eve made clothes for themselves. Presumably by the time Adam talks to God in 3:10 he has already covered himself. A rabbinic commentary Or Ha-Chaim explains the fear Adam had in encountering God by his understanding of the wrongness in violating God's prohibition. The fear of nudity which he confesses should be taken metaphorically: Adam was no longer covered by 'divine shining', and he knew it. He was then ashamed not of any sexual impropriety allegedly intrinsic to his bodily nakedness, but of a purely moral failure in eating the forbidden fruit. It is debatable whether he could be blamed and punished for that failure. If we follow Velleman's interpretation, prior to eating the fruit Adam had no capacity of choice, and so could not take responsibility for his actions, nor did he even perform any action in the full sense of the word. ${ }^{11}$ Blameable or not, Adam now came to occupy a lower moral level than before, and the awareness of that fact produced his shame.

This suggestion sits much better with $\mathrm{H} 1$ or $\mathrm{H} 3$ than with A3. Upon eating the fruit Adam had a lower self-esteem than before, but the reason of this drop was his prior acceptance of a certain norm. It did not have anything to do with the conflict between will and desire.

Shame in the state of nature. Complaints about a proper reading of Genesis may sound captious. After all, Velleman does not intend his Biblical scholarship to play any major theoretical role. Its theological context can distract our attention from the philosophical puzzle. Let us then pose the question in general: how is the experience of shame to be explained in the conditions devoid of social norms, such as the conditions of the state of nature? Velleman believes that the explanation is the same as within the society:

11 This is not the interpretation favoured by Augustine. In XIV.13 he claims that Adam was already corrupted by the sin of pride and was perfectly capable of decision and choice. 
Even Robinson Crusoe chose which of his desires to act on, and his need to understand and coordinate his activities required him to make choices by which he could consistently abide. He therefore lived in accordance with a persona that he composed, even though there was no audience for whom he composed it. Or, rather, he composed this persona for an audience consisting only of himself, insofar as it was designed to help him keep track and make sense of his solitary life. So even Robinson Crusoe had distinct overt and covert selves - the personality that he acted out, and a personality that differed from it by virtue of including all of the inclinations and impulses on which he chose not to act. (Velleman, 2006a:53)

We can certainly agree that even in the state of nature the agent should be able to choose which desires to act on, and that such a choice is a demonstration of his will and of its control over the multitude of desires. Should it, however, follow from this fact alone (Velleman's 'therefore') that the agent thereby creates public and private images of himself? If Velleman is right, then, inevitably, Robinson Crusoe had the idea of privacy. And this inference is stretched.

In the first place, Robinson Crusoe would resist many desires for tangibly instrumental reasons. He would, for example, resist the strong urge to consume his fish catch at once and would instead divide its consumption over a week. The fact of this successful resistance, as far as I can see, is simply irrelevant to whatever self-presenting profile he putatively elected to create and maintain. To take an intuitively more relevant case, suppose that Crusoe had to masturbate, and that he masturbated only unwillingly. By Velleman's lights, when an agent performs such unwilling acts, he will try to do so in privacy. When he is exposed to the public, shame will ensue. Are we then to conclude that Crusoe masturbated in his hut, rather than on the beach or in the forest? Conceivably soon after the shipwreck he would be reluctant to do this in the 'open', and so he would still separate between the private and the public. As time went on, and as his adherence to his former social norms was getting looser, he would (or so I predict) no longer separate between the two areas and masturbate in any suitable place.

We can understand, in other words, how an agent cast outside the society would separate between the desires in which he would be willing to engage and in which he would not. But it is hard to 
understand what the public and the private separation would consist in, and how a shame experience would be possible when the norms begin to fall off. And while that separation need not be merely geographical, it is at the same time unclear how it could survive without some such element. The bare fact of resisting certain desires is not sufficient for maintaining the separation.

Perhaps, on the other hand, this criticism is unfair, since it ignores the other theme of Velleman's argument: to create a public image of oneself, and to maintain it, is essential for 'keeping track and making sense' of one's life. So not every desire conflicting with the will is apt to generate shame. Giving in to your desire to consume your fish catch all at once is shame-neutral, so far as it does not interfere with your capacity of making sense of your life. This necessary correlation between shame and the meaning of life remains, however, under-developed in Velleman's theory. It is, for example, not clear whether it exists in the average conditions of social life. Moreover, it is not quite certain, I think, that the conceptual resources Velleman's theory commands would be enough to defend the correlation. I do not see how the ability for self-presentation and the creation of a public image should, on their own, provide the agent with a better understanding of his life (and motivate him to go on with it).

What, I think, is much more certain is that a Hobbesian would encounter few difficulties in explaining Crusoe's shame. It is possible to imagine Crusoe's shame, but a well-hidden assumption in such imagining, according to the Hobbesian, is the emergence of a norm. That norm - 'it is wrong to engage in masturbation' - could be inherited by Crusoe from his earlier life or could have been re-created in the course of his island existence. As soon as the norm was established in that society of one, it became a factor in Crusoe's self-esteem. And as soon as his self-esteem included a norm to which he had to conform, shame became possible.

This explanation is better suited to account for the fact that a coherent behaviour would be conducive to Crusoe's making sense of his life. Such norm-driven behaviour will provide him with the reasons to go on, because the norm would be an expression of value. His daily routine would be put in the service of the values underlying those norms. Since the link between the agent's values and his self-esteem is straightforward, the protection of selfesteem becomes essential for supplying him the with reasons for going on with his life. The occasions of shame would then be the 
occasions of undermined self-esteem and also the occasions of betrayed values. Once the betrayal becomes frequent, while the values remain constant, the reasons for going on with his life will gradually fade away.

Should norms require an Augustinian explanation? One problem with the Hobbesian view such as $\mathrm{H} 3$ is that the reasons of shame are tied to a canon of norms, and while we can cite reasons for the prevalence of this or that individual canon, there is no unifying reason for their adoption in different communities. Which behavioural patterns are deemed shameful is, to this extent, arbitrary. Is this plausible? One might very well protest and demand a deeper explanation of existent norms. So the Augustinians may aim at gaining an advantage over the Hobbesians by filling the lacuna and locating a unifying explanation of shame. In doing that the Augustinians would also be able to respect the central insight of the Hobbesian view, the link between shame and self-esteem.

The theory A3 is designed to offer such a unifying explanation. Begin with the simple Augustinian premiss: agents are able, through their will, to control and resist their desires. However, on some occasions, the reason they exercise control is to protect their self-presenting image. This image is necessary for them to count as social agents. And the reason they should count as social agents is the fulfilment of cooperation requirements. Certain desires, when effective, make them unsuitable candidates for social cooperation. It is true, therefore, both that shame is a social phenomenon, being an offshoot of social cooperation, and that it is necessarily related to the conflict between will and desire.

However, the story of Robinson Crusoe, as narrated earlier, tells against this inference. Crusoe controlled his desires, but, on some occasions, the purpose of such control was merely instrumental. It could be useful for Crusoe's survival, but incapable of generating shame (fish catch). On other occasions, control was relevant to shame, but not related to survival (masturbation). It should, however, have been related to the adoption of a norm. In neither case cooperation was in play, since Crusoe had no one to cooperate with.

But perhaps a defender of A3 should rather start from the Hobbesian premiss linking shame to self-esteem, in the hope to eventually link it to the properties of agency. Suppose that shame is functionally dependent on your self-esteem which (in most cases) depends on the judgement of others. But the way this 
judgement is formed is not arbitrary. Conceivably nudity is frowned upon because of intelligible anthropological reasons. A naked male individual, unable to control and hide his erections, is not the best candidate for a wide range of social roles and activities. His predicament may well be the source of the rather strict norms of covering parts of your body. The shame of nudity, on this assumption, would be a remote outcome of awkward erections. So, if $A$ explains $B$, and $B$ explains $C$, then $A$ explains $C$ : if cooperation requirements explain the norm of covering parts of your body in public, and if this norm explains the shame of public nudity, then those requirements must explain the shame of public nudity. Analogous inference would be urged to explain, for example, the shame of intellectual inadequacy.

This line of argument also founders: there is no required transitivity of explanation. The emergence of a certain norm may have an anthropological explanation. At the same time the reason why many people follow, or endorse, the norm much later may have nothing to do with the reasons of its initial acceptance. Some may be unable to provide any reasons at all, while others will follow it out of the religious conviction. Shame, if it is induced by the violation of a norm, might not at all be related to the anthropological reasons which led to the entrenchment of that norm. It may be related to nothing more than the bare fact of the norm's acceptance by the agent himself and by the people in the agent's environment.

Nudity and nudists. The point about explanation can be reinforced further by looking again at the relation between privacy and nudity. Suppose that Ludovic's clothes accidentally fall off and all of a sudden he finds himself naked in public. His experience is that of shame, meeting the requirements of A3. Yet I do not see how his situation undermines his capacity for social cooperation. The audience may understand perfectly well why the clothes fell off (it was an accident), but that would not diminish the shame. By contrast, other than the protection of his cooperative capacity, Velleman's account does not give Ludovic any reason to control his desires and to maintain his privacy. And where that capacity is not threatened, shame is not an appropriate reaction. Ludovic's case seems to imply that this threat to cooperative agency is not even a necessary condition of shame.

What, on the other hand, should we say of those people who, like nudists or Playboy models, deliberately choose to strip in 
public? Unlike Ludovic, they experience no shame on the account of their nudity. The difference between Ludovic and a nudist, on Velleman's view, is that one, in his nudity, fails to maintain his public image, while the other's public image is left intact. That much may be true. But it remains mysterious why the violated public image of an unwilling nudist, such as Ludovic, makes him a less worthy candidate for social interaction than a nudist who walks naked for hours and whose public image is intact. On any sane view, a nudist is actually a less suitable such candidate than the unfortunate Ludovic. Perhaps Velleman should rather argue, implausibly, that a nudist - a male nudist in particular - must always experience natural shame, even though the dominant social norms may significantly reduce its intensity. ${ }^{12}$

Observe, however, that the mystery would never arise had we claimed that the nudist believed himself to be a no less worthy social actor on the account of his nudity, but that Ludovic believed himself to be a less worthy social actor precisely because of his nudity. To couch the explanation in terms of what the agents believe about their social status, rather than in terms of the status itself, is to appeal to a procedure of self-evaluation. The agent values himself in accordance with his belief of what value should be ascribed to a pattern of behaviour, or to any quality in general, and also in accordance with his belief of which qualities he in fact possesses. Shame is then interpreted as one possible outcome of such procedure. This is the same procedure outlined in $\$ 1$ that characterises Hobbesian theories of shame.

Natural shame. Velleman argues both that naturally shameful situations involve desires disobedient to the will, and that natural shame can be modified by social norms:

Adam and Eve's shame might still have reflected an observer's assessment if they thought of themselves as being judged by a natural rather than social ideal [. . .]. (47)

Although deliberate self-exposure doesn't necessarily occasion shame, there remains a sense in which public nakedness is naturally suited to occasion it and can therefore be called naturally shameful. What makes nakedness naturally shameful, I think, is the phenomenon adduced by St. Augustine - namely, the body's insubordination to the will. (56)

12 Velleman's remarks on male body appear to move in this direction. See Velleman (2006a:56-57). 
[Nakedness and blushing] are naturally shameful only in the sense that they involve bodily insubordination, which is naturally suited to undermine self-presentation and thereby to cause the relevant sense of vulnerability. But which failures of self-presentation actually cause a subject to have or to feel this vulnerability can be modified by social norms. (61)

The distinction between natural and social shame is acknowledged in the condition (iii) of A3: the public image is largely, but not entirely, composed out of the desires to be satisfied in public. One benefit of this distinction is in addressing the kind of concern raised in $\$ 2$ with regard to A1. Intellectual inadequacy, for example, does not involve desires insubordinate to the will. While, for this reason, it is not naturally shameful, it could still be socially shameful, so long as it could undermine the agent's selfpresentation within a society. The explanation of what we deem shameful can appeal directly to the will and desire conflict, or it can refer instead to social norms. ${ }^{13}$ Secondly, different audiences demand different standards of self-presentation. Coughing at a classical concert constitutes a certain failure to self-present, but is entirely inconsequential at a rock concert. Self-presentation profiles should be flexible and sensitive to the given context. The natural/social shame distinction is an instrument for accounting for this flexibility. Both social shame and natural shame, however, point in the same direction - towards the same demand of a coherent self-presentation.

On this view, then, ( $a$ ) not every situation which is actually shameful (i.e. recognised by us as such) is naturally shameful. Should we, however, also say $(b)$ that not every situation which is naturally shameful (in Velleman's sense of it) is of necessity actually shameful? If both claims are true and if modifications engendered by norms can make naturally shameful situations not actually shameful, and vice versa, it is unclear just what role the concept of natural shame is supposed to play in the theory A3. For there would be no reason to suppose, not before a further argument is given, that natural shame and actual shame always overlap, let alone that natural shame can explain actual shame. With appropriate modifications, no member of the original set of naturally shameful situations would be counted as actually shameful.

13 This move, I believe, is not sufficiently appreciated by the critics. See, e.g., Deonna et al. (2012:143). 
And as far as I can see, the claim $(b)$ is true. Consider food consumption. More exactly, think of yielding to your desire and indulging yourself with an extra slice of cake. This occasion should in fact be one of natural shame. Even though it need not involve a total surrender resulting in unrestrained gluttony, yielding to your desire would ensure the natural shamefulness of this action on a par with the shamefulness of a sexual intercourse. It follows that, in general, desserts should better be eaten in private.

Well, this attitude may be commended for its consistency. ${ }^{14}$ Yet its absurdity is obvious none the less. We are not in the least compelled to regard public eating and drinking as shameful as public sex. In our society, in any event, they are hardly shameful at all (unless we reach the extremes of drunkenness and gluttony). This presumably is because the scope of shame within a society is imposed by the norms of that society, rather than by the theory of will and desire. And thus, in confirmation of our hypothesis, social norms can mark the (putatively) naturally shameful situations as not shameful. Of course, our result allows for a possibility of intersection between natural shame and actual shame. Public sex, for example, is both naturally shameful and actually shameful. But any such intersection would reflect a merely contingent correlation. What we recognise as shameful would no longer be explained by natural shame.

\section{Shame, embarrassment, and self-presentation}

So far I have defended the following claims. (1) The classical Augustinian theory of shame is materially inadequate. It does not classify as shameful those situations that we are apt to recognise as shameful. (2) Velleman develops the Augustinian approach and places the interaction between will and desire at the heart of the theory of shame. But the explanations it offers are unconvincing. Moreover, (3) they tend to be inferior to the explanations offered by Hobbesian theories. (4) Velleman's view relies on the distinction between natural shame and social shame. However, the former notion turns out to be theoretically idle.

At this point it is worth recalling why the concept of natural shame was introduced in the first place. Natural shame is

\footnotetext{
14 See the striking anecdote about R. Pinchas ben Yair narrated by Maimonides in the Guide for the Perplexed III.8.
} 
supposed to be explained entirely in terms of the relation between will and desire and its effect on self-presentation. The core cases of shame were supposed to be the cases of natural shame, while on the periphery we were to allow social modifications to adjust the boundaries of shame experience. These adjustments were required to ensure the material adequacy of the theory and to deal with the situations where no evident psychic conflict was in play. Dispensing with natural shame, we can now delete the clause (iii) of A3 that places the voluntary control of desires at the heart of the theory. We get the result that the explanatory job will be done entirely in terms of self-presentation:

H5. Shame is a response to a failure of coherent selfpresentation.

Unlike $\mathrm{H} 4$, the present view does not make shame a matter of a falling reputation determined by the contingent norms of the agent's society whose common source, even if it exists, is not properly part of the explanation. Shame will rather be a matter of an incoherent self-presentation that the agent projects in social interaction. The experience of shame so understood will receive an explanation invariant under particular norms, since such an explanation will be able to bypass them and appeal directly to the overarching norm of coherence. What counts as a coherent selfpresentation would still be context-sensitive, but only in the sense that different social structures would implement the same norm of coherence in different ways. The norm of coherence itself is not a brute fact, but can be explained, e.g., by its tendency to increase the chances of survival.

Since this view, no less than H4, would disconnect Velleman's ideas from their Augustinian source, perhaps we should conclude that Velleman was mistaken in tracing their origin. The emphasis he placed on the role of will and desire was spurious. He tried to make a case for A3, but was only successful in defending H5. In fact the précis of the original article suggests more clearly than any passage in the article itself that Velleman's real view may indeed be $\mathrm{H} 5$ :

[S] hame is anxiety that we feel about a threat to our socially recognized status as self-presenting creatures, a status that ultimately rests on the structure of a free will, in virtue of which we qualify as persons. This threat can arise from the exposure of 
particular discreditable qualities, of which we are then said to be ashamed, but it can also arise in the absence of any perceived demerit. [...] These instances of shame are possible, I claim, because the object of anxiety in shame is not our distinctive personality but rather our social standing merely as self-presenting persons. Hence understanding shame requires acknowledging the importance of being somebody - in this case, the importance of being somebody to others. (Velleman, 2006b:10, italics added)

There is a reference to the will, but the sense in which selfpresentation "rests on the structure of a free will", one suspects, is rather ambiguous. Free will is one of the enabling conditions of self-presentation, so far as the latter is a deliberate purposive activity requiring a measure of self-control. Yet when we come to the explanation of shame, its object ought to be the failure of self-presentation itself, rather than the cause of that failure, or the impact it allegedly has on our status as free agents. We have encountered this problem earlier in page 8: explanatory reasons are not transitive. The reason of shame is the failure of selfpresentation, but the reason of that failure does not have to be, and often is not, the reason of shame. The shame of intellectual inadequacy is a case in question. And if Velleman realised that, as perhaps he eventually did, his formula of shame should omit reference to the will. And if so, then his lengthy exploration of the Eden drama and of the Augustinian view is just a distraction, a rhetorical ploy at best.

Another problem with this interpretation is that it contradicts Velleman's own declared goal. This is because at the outset Velleman explicitly distances himself from the 'reflected selfassessment' view of shame, a view which attributes shame to the way the subject appears to others. ${ }^{15}$ Now it is reasonable to assume that the subject manages his self-presentation, evaluates its success and failure, to a great extent according to the expectations and reactions of the audience. These expectations and reactions will vary in different contexts, but the entire purpose - or certainly one of the dominant purposes - of self-presentation is to fit and accommodate one's behaviour to the standards by which the others would judge this behaviour. I do not see, therefore, how H5 cannot fail to be an attempt at articulating a 'reflected

\footnotetext{
15 In a lengthy footnote 1 Velleman ascribes this view (wrongly, I think) to Taylor, Rawls, and Williams, among others.
} 
self-assessment' view of shame. But then, to impute it to Velleman (2006a) would mean to undermine its original motivation.

These are tentative claims in exegesis. What of the substance? The main philosophical problem with $\mathrm{H} 5$ is that it gives an account of embarrassment, rather than of shame. Indeed, it bears a strong resemblance to the classical view developed in Goffman (1967a) ${ }^{16}$ I am able to give only a briefest summary of that view. Embarrassment, according to it, is a phenomenon belonging essentially to social encounters (where 'encounter' should be understood very broadly and traced, I think, to Simmel's Wechselwirkung). Every participant in these encounters, by the fact of his participation, 'takes a line'. Even if it is not his purpose, he de facto expresses his attitude to the situation and his evaluation of the other participants and of himself. He forms an idea of what sort of attitudes, behaviour, abilities, and knowledge is expected of him. Similarly, other participants have formed their expectations of him along the same parameters. When the expectations are unfulfilled, when the agent performs either below or above the expectations, embarrassment ensues. ${ }^{17}$ Thereupon the encounter is thrown into a disarray, until the evaluations are again revised in accordance with expectations, and the equilibrium is restored.

Several elements of this theory hold special interest for us here. (1) Embarrassment involves evaluation of one's self and of other selves involved in the encounter. But this evaluation is extremely local. Embarrassment is not provoked by the re-appraisal of one's value as a person. No revision of any parameters of self-evaluation need be involved in it at all. An embarrassed agent only appraises his standing in the concrete encounter. To be sure, severe cases of embarrassment may be taken as symptoms of a deeper malaise and subsequently cause a re-appraisal. This means perhaps that embarrassment may cause shame (at least if we are to side with the Hobbesians), but not that the two are the same. (2) Embarrassment is pervasive. This is one of the finer consequences of Goffman's analysis. Intuitively we believe that to have poise and composure is to behave 'naturally'. Their loss in embarrassment is thus thought to be unnatural. But in fact they are no more natural than keeping your balance on a tightrope is. The self is constantly

16 For the important background discussion see Goffman (1967c). A similar criticism of Velleman is made in Deonna et al. (2012:142) where the authors omit any reference to Goffman, however. See also footnote 18.

17 See Goffman (1967a:105) and also Goffman (1967c:5). 
under scrutiny (being 'monitored', as Goffman says) in a social encounter. As the encounter progresses, the individual's own expectations and the expectations of others are liable to be revised. His claims for possessing certain qualities will tend to be discredited, at least in part. That will induce either his own embarrassment or the others' embarrassment for him.

Is shame nothing but embarrassment so interpreted? The difference between the two emotions is not in their intensity: as we all know, embarrassment can be extremely painful. It is not merely a weak form of shame. Nor is it shallow, if this means that the embarrassed individual is a deceiver, concerned with mere appearances and not with how he really is. ${ }^{18}$ It is not as though in my social encounters I merely want to appear polite (or welldressed etc.), whereas in reality I am not. This distinction is incoherent: to be polite $i$ s to be polite in social encounters. Nevertheless there is a sense of superficiality in embarrassment. It is in that, on many occasions, the qualities causing embarrassment cannot be the genuinely important qualities underpinning the individual's self-esteem. They are manifestations of these deep qualities. Thus civility is supposed to be a sign of good upbringing, while good upbringing is supposed to be a cause of elevated moral character. So civility can be taken as a sign of elevated moral character (of course, such connections can be symmetrical and need not be unique). Embarrassment on those occasions has as its object these manifestations, rather than the deep qualities. The objects of shame, on the other hand, are the deep qualities themselves.

Secondly, if we were to identify shame with embarrassment, then shame would emerge somewhat trivialised. ${ }^{19}$ We think of shame as a relatively rare experience. Its rarity, I suggest, is due to the procedure of reflective self-evaluation and re-evaluation involved in it. In shame we pass a judgement on ourselves. There is a certain cognitive distance between this judgement and the judgement of how we perform in the given interaction. A virtuoso pianist stumbles in his public performance. The error becomes evident to everyone. He is embarrassed, and so should be his audience. His shame might follow right away, as he realises his deficiency as a pianist. It might follow later on when he reflects on the error in his hotel room. Or, far more likely, it will not follow:

\footnotetext{
18 Here I disagree with Deonna et al. (2012:115-116).

19 It has to be said that Goffman, himself not being interested in shame, does not attempt to distinguish it from embarrassment.
} 
he brushes the incident aside on the grounds that 'this can happen to anyone' (as Richter once did). This attitude does not clash with the fact of the earlier embarrassment. There are also good reasons why shame should not be trivialised. If shame were a constant fixture in social interactions, not only these interactions would be too taxing for us, but also they would become essentially about ourselves (and our selves). Social unease generated by the discredited self-presentation can be easily overcome in part because it only infrequently undermines our self-esteem, not reaching our deep qualities.

The theory $\mathrm{H} 5$ cannot be accepted as an account of shame. But the two objections just stated also suggest a remedy. If one were to insist on a special link between shame and self-presentation, one might modify $\mathrm{H} 5$ as follows:

H6. Shame is a response to a drop in self-esteem occasioned by a failure of coherent self-presentation.

This view belongs squarely in the Hobbesian camp. Shame, according to it, involves a re-appraisal of oneself, but only such that is prompted by a failing self-presentation. At a luncheon party Lady Edgware misunderstands the expression 'judgement of Paris' taking 'Paris' to refer to the city and its world of fashion, rather than to the son of Priam. It is a faux pas creating embarrassment. Lady Edgware presented herself as an educated person, and the expectations of the people at the party were set accordingly. Now these expectations had to be adjusted. A few minutes later, as she takes in what has just transpired, she may become aware of her inferior education (contrary to the actual plot of Agatha Christie's story). As this awareness grows, she recollects other similar incidents. Shame is her reaction: she is ashamed of the kind of person she is.

If that is how $\mathrm{H} 6$ portrays the emergence of shame, then the focus of shame is a parameter in one's self-esteem ('being educated', 'being cultured'). But embarrassment is posited as its necessary cause. This, I think, is a highly welcome development. For it will explain why embarrassment is often identified, wrongly, with shame. As in many other cases, one is apt to confuse a causal relation with the relation of identity. Though embarrassment does not always cause shame, shame is always preceded by embarrassment. The analysis based on $\mathrm{H} 6$ would integrate the theory of embarrassment into the theory of shame. Another benefit is that 
shame can be distinguished from self-disappointment. The latter would be interpreted as a response to a drop in self-esteem that is not occasioned by a self-presentation failure. Thirdly, since the self-presentation profile, for reasons already mentioned, is created on the basis of extant norms, shame will be dependent on those norms. We would be able to explain why the parameters of self-esteem featuring in the experience of shame must be such as to correspond to those norms. This will be an improvement on a view such as $\mathrm{H} 3$.

Here is not the place to debate either of these claims. None the less, because of its significance, let me try to sketch a way for distinguishing shame from self-disappointment. Suppose that a painter considers creative activity the most important value. Accordingly, it plays a pivotal role in his self-evaluation. His selfesteem depends, first and foremost, on his perception of how good a painter he is. He does not endorse this value merely because it is appreciated in his milieu. The painter, you see, is an individualist generally disinclined to follow socially approved norms in his self-evaluation. However, when one day he pauses to reflect on his artistic output, he realises that its quality is not good enough. We are apt, I think, to interpret his reaction as one of self-disappointment. How can the same kind of understanding provoke shame? According to $\mathrm{H} 6$, we should look into its causal history. The painter arranges an exhibition of his work. He invites his friends, but hardly anyone else shows up. Those who do leave soon. To this situation the painter's reaction is embarrassment. But if soon afterwards it prompts the same realisation of low achievement and a drop in self-esteem, we have the experience of shame. Essential to this strategy is the ability to isolate causal relations. The bare fact of poor attendance of the exhibition may be seen as evidence of the painter's artistic failure. This fact, on its own, will trigger self-disappointment. If, on the other hand, the fact of embarrassment causes re-evaluation, then we are in a situation of shame.

Further examination is required to establish $\mathrm{H} 6$ as a serious contender in the debate. It will lead us too far afield. All the same, already within the limits of our present discussion we can see that it offers intriguing new ideas in the resolution of some central issues in the philosophy of shame.

Let me close, however, by stressing that $\mathrm{H} 6$ could not plausibly be read into Velleman (2006a), even less so than H5. (a) As already mentioned, the conflict between will and desire is a 
contingent ingredient of embarrassment. It is not, properly speaking, an ingredient of shame. Rather, $(b)$ as in the basic Hobbesian model, H6 explicates shame by appeal to self-esteem. This fixes a point of departure completely different from Velleman's argument. $(c)$ There is a sense in which shame causally depends on how the subject is seen by others. This means that $\mathrm{H} 6$ preserves the insights of the 'reflected self-assessment' theories, an ostensible target of Velleman's polemic. And $(d)$ privacy would only have a secondary role in shame. The concern for privacy is indeed a concern in embarrassment, but not essentially so. Perhaps one could say that Lady Edgware was embarrassed because her ignorance was laid bare for all to see, and that even there we have an instance of privacy violation. Clearly, though, there is no such violation in the pianist's embarrassment or the painter's embarrassment. When we come to shame, $\mathrm{H} 6$ sees privacy as a possible element in its causal history. Self-esteem remains its proper central concern. ${ }^{20}$

\section{Department of Philosophy \\ Bilkent University \\ Ankara 06800 \\ Turkey \\ sandy.berkovski@gmail.com}

\section{References}

Darwin, C. (1890). The Expression of the Emotions in Man and Animals. John Murray.

Deigh, J. (1996). Shame and self-esteem: a critique. In The Sources of Moral Agency. Cambridge University Press.

Deonna, J. A., Rodogno, R. and Teroni, F. (2012). In Defense of Shame. Oxford University Press.

Gibbard, A. (1990). Wise Choices, Apt Feelings. Clarendon Press.

Goffman, E. (1967a). Embarrassment and social organization. In Goffman (1967b).

- (1967b). Interaction Ritual. Pantheon Books.

- (1967c). On face-work. In Goffman (1967b).

Jacoby, M. (1994). Shame and Origins of Self-esteem. Routledge.

Kekes, J. (1993). The Morality of Pluralism. Princeton University Press.

Miller, W. I. (1993). Humiliation. Cornell University Press.

Rawls, J. (1999). A Theory of Justice. Harvard University Press, revised edition.

Taylor, G. (1985). Pride, Shame, and Guilt. Clarendon Press.

Tomkins, S. S. (2008). Affect Imagery Consciousness: The Complete Edition. Springer.

Velleman, J. D. (2006a). The genesis of shame. In Velleman (2006b).

- (2006b). Self to Self. Cambridge University Press.

Williams, B. A. O. (1993). Shame and Necessity. University of California Press.

20 I am grateful to James Alexander, Yasemin Topac, Jack Woods, and an anonymous referee for helpful comments on a previous version of this paper. 